\title{
Response to letter to editor
}

\author{
I. R. Reid • M. J. Bolland
}

Received: 3 August 2014 / Accepted: 4 August 2014 /Published online: 13 August 2014

(C) International Osteoporosis Foundation and National Osteoporosis Foundation 2014

We agree that absorption of calcium from the gut, under the regulation of intestinal vitamin D receptor (VDR), is critically important for bone health through the prevention of osteomalacia in adults and rickets in children. We also agree that administering excessive amounts of vitamin D may have deleterious effects on bone, via the effects of VDR in bone on mineralization and/or bone resorption.

The authors suggest that calcium is necessary for vitamin $\mathrm{D}$ to improve bone health. However, all diets have some calcium in them, so this does not mean that calcium supplements are necessarily required. Fracture data from trials suggest that the effect of calcium plus vitamin D is comparable to that of calcium alone [1], but calcium with or without vitamin D increases cardiovascular risk to an extent which negates any bone benefit [2].

With respect to the Priemel study, those authors measured indices of bone turnover rather than mineralization (which requires in vivo labelling) and assessed vitamin D status in postmortem samples, which are likely to be misleading because of the rapid response of 25-hydroxyvitamin D to trauma or inflammation [3]. Other difficulties in generalising results from this postmortem study to living people have been raised previously [4].

The results of ongoing vitamin $\mathrm{D}$ trials may be of limited value, since our recent trial sequential meta-analyses suggest that new data are unlikely to change the conclusions of current meta-analyses, because of the substantial body of negative data that already exists $[5,6]$. The authors' final sentence raises an interesting point: when there is a large body of evidence from randomised controlled trials with meaningful

I. R. Reid · M. J. Bolland

Department of Medicine, University of Auckland, Auckland, New Zealand

I. R. Reid $(\bowtie)$

Faculty of Medical and Health Sciences, University of Auckland, Private Bag 92019, Auckland, New Zealand

e-mail: i.reid@auckland.ac.nz clinical endpoints that rules out important clinical effects [5-9], at what point is there enough evidence to state that an intervention is not effective?

Acknowledgments Supported by the Health Research Council of New Zealand.

Conflicts of interest None.

\section{References}

1. Tang BMP, Eslick GD, Nowson C et al (2007) Use of calcium or calcium in combination with vitamin $\mathrm{D}$ supplementation to prevent fractures and bone loss in people aged 50 years and older: a metaanalysis. Lancet 370:657-666

2. Bolland MJ, Grey A, Avenell A et al (2011) Calcium supplements with or without vitamin D and risk of cardiovascular events: reanalysis of the Women's Health Initiative limited access dataset and meta-analysis. BMJ 342:d2040

3. Reid D, Toole BJ, Knox S et al (2011) The relation between acute changes in the systemic inflammatory response and plasma 25hydroxyvitamin D concentrations after elective knee arthroplasty. Am J Clin Nutr 93:1006-1011

4. Aspray TJ, Francis RM (2013) What can we learn about vitamin D requirements from post-mortem data? Osteoporos Int 24:1769-1770

5. Bolland MJ, Grey A, Gamble GD et al (2014) Vitamin D supplementation and falls: a trial sequential meta-analysis. Lancet Diabetes Endocrinol 2:573-580

6. Bolland MJ, Grey A, Gamble GD et al (2014) The effect of vitamin D supplementation on skeletal, vascular, or cancer outcomes: a trial sequential meta-analysis. Lancet Diabetes Endocrinol 2:307-320

7. Reid IR, Bolland MJ, Grey A (2014) Effects of vitamin D supplements on bone mineral density: a systematic review and meta-analysis. Lancet 383:146-155

8. Autier P, Boniol M, Pizot C et al (2014) Vitamin D status and ill health: a systematic review. Lancet Diabetes Endocrinol 2:76-89

9. Theodoratou E, Tzoulaki I, Zgaga L et al (2014) Vitamin D and multiple health outcomes: umbrella review of systematic reviews and meta-analyses of observational studies and randomised trials. BMJ 348:g2035 